\title{
Ensino de ciências e matemática: utilização da informática e formação de professores
}

\author{
Fernando Temporini Frederico ${ }^{1}$, Dulcinéia Ester Pagani Gianoto ${ }^{2}$
}

\begin{abstract}
Resumo: Este artigo discute a utilização dos laboratórios de informática e também, de alguns softwares computacionais que podem contribuir com a construção de conhecimento de conceitos ligados às disciplinas de ciências e matemática. Para tal, foi realizado uma pesquisa em duas escolas estaduais no Município de Barbosa Ferraz - PR, para verificar com que freqüência os laboratórios de informática são utilizados pelos professores e, principalmente, evidenciar que tipos de ferramentas são exploradas nestes laboratórios. Os resultados mostram que o uso do laboratório nestes estabelecimentos de ensino tem se resumido quase que exclusivamente a pesquisas na internet. Neste sentido, acreditamos que é necessário que se criem meios para que estes recursos, tão importantes nos dias atuais, sejam explorados com mais eficiência, dando condições para que a tecnologia possa colaborar com a construção do conhecimento de forma significativa.
\end{abstract}

Palavras-Chave: tecnologia educacional; softwares; formação de professores.

\section{Science and Math Teaching: Use of Information Technology and Teacher Education}

\begin{abstract}
This article discusses about the use of computer laboratories and computer softwares that may contribute to the knowledge construction of concepts linked to the subjects of Sciences and Mathematics. For this reason, a research was performed in two state schools in Barbosa Ferraz - PR, in order to verify with what frequency computer laboratories were used

${ }^{1}$ Doutorando do Programa de Pós-Graduação em Educação para a Ciência e a Matemática - Universidade Estadual de Maringá (UEM). Professor de Física e Matemática da rede estadual paranaense. ftfrederico@gmail.com

${ }^{2}$ Doutora em Educação para a Ciência. Universidade Estadual Paulista (Unesp/Bauru). Professora do Programa de Pós-Graduação em Educação para a Ciência e a Matemática - Universidade Estadual de Maringá (UEM).depgianoto@uem.br
\end{abstract}


by teachers and, mainly, to evidence which type of tools were explored in these laboratories. Results show that the use of laboratory in these teaching establishments has been almost resumed to internet research. In that sense, we believe it is necessary to create means for these resources, so important nowadays, to be more efficiently explored, providing conditions for technology to collaborate with the knowledge construction in a significant way.

Key words: educational technology; softwares; teachers formation.

\section{Introdução}

Nos dias atuais, torna-se difícil falar em educação sem fazer referência às tecnologias. Isso porque a escola, assim como muitos outros segmentos da sociedade, está permeada por ela.

A profissão de professor, por sua vez, parece estar sempre vinculada aos livros, ao giz, ao quadro-negro. Entretanto, nos últimos anos, essa convicção tem mudado bastante, o que talvez se justifique em razão da diversidade de recursos didáticos disponíveis, principalmente os audiovisuais.

Parcela considerável dos alunos que integram a "realidade regional"3 tem acesso a tecnologias de informação e comunicação, como computadores, celulares, internet, entre outros aparatos tecnológicos. O computador, certamente, é uma das ferramentas que melhor representa a tecnologia contemporânea. Muitas pessoas realizam, cotidianamente, ações que envolvem seu uso, desde as mais simples, como redigir um texto, acessar um e-mail, até mais complexas, tais como simulações de fenômenos naturais, cálculos numéricos com muitas variáveis, entre outras.

Praticamente, todas as escolas públicas do estado do Paraná possuem um laboratório de informática e, em muitas delas, sua utilização ainda é questionada

${ }^{3}$ Fazemos questão de enfatizar aqueles indivíduos que moram na região sul-sudeste do Brasil, pois, mesmo no século XXI, devido a fatores de ordem diversa, ainda há um universo considerável de pessoas que não têm acesso a algumas tecnologias, como é o caso da internet. De acordo com o IBGE (2013), o acesso à internet cresceu 143,8\% entre a população com 10 anos ou mais, de 2005 para 2011, enquanto o crescimento populacional foi de 9,7\%. Apesar da disparada, 53,5\% dos brasileiros dessa faixa etária ainda não utilizam a rede. 
por alguns educadores que aparentam ter certa resistência a seu uso. Desde o ano de 2003, a Secretaria do Estado da Educação do Estado do Paraná - SEED -, com a colaboração da Universidade Federal do Paraná - UFPR - e da Companhia de Informática do Paraná - CELEPAR -, inseriu nas escolas paranaenses laboratórios de informática, com uma infraestrutura de equipamentos (four head) 4 e com um sistema operacional em software livre (Paraná, 2010). A conexão desses laboratórios ocorreu por meio de fibra óptica, o que possibilitou a instalação dos computadores e da internet nos lugares mais remotos do estado.

Nossa experiência como educadores nos possibilita observar que o uso desses laboratórios se limita, muitas vezes, a pesquisas na internet e a outras atividades on-line. A exploração do editor de textos, as planilhas de cálculos e outros softwares passam quase despercebidos.

Isso nos leva a refletir sobre duas hipóteses - primeira: muitos educadores não dominam adequadamente o computador e algumas das suas múltiplas ferramentas, que podem ser utilizadas a favor da educação; e segunda: não gostam e não querem utilizá-las. De repente, diante da primeira hipótese, a justificativa mais plausível talvez seja que, devido à extensa jornada de trabalho que lhe é atribuída, o professor não tenha tempo hábil e disponível para preparar suas aulas, nem tampouco, para projetar atividades que façam uso do computador e, especialmente, para se capacitar para isso.

De acordo com Mercado (2002), não basta colocar os computadores à disposição dos professores, mas é preciso preparar o docente, respeitar seu tempo e, principalmente, fazer com que ele entenda o porquê de uma ferramenta nova de trabalho.

Já, Carneiro (2002) nos alerta que é importante que os alunos, os professores e os educadores estabeleçam um compromisso prazeroso com as novas tecnologias e que percebam a importância de "despir-se das resistências". Estas palavras nos levam a refletir sobre a segunda hipótese, em que se percebe que, ainda hoje, muitos professores não conseguiram superar alguns paradigmas metodológicos que ignoram a presença, no seio escolar, dessa tecnologia que poderá influenciar na vida social dos estudantes, tanto dentro quanto fora da escola, especialmente quando se fala em primeiro emprego.

\footnotetext{
${ }^{4}$ Pelo sistema FourHead, em cada máquina são ligados quatro teclados, quatro mouses e quatro monitores. Assim, até quatro pessoas podem usar o computador ao mesmo tempo.
} 
Desse modo, é indispensável que os alunos concluam o Ensino Médio, preparados para dar continuidade aos estudos e, principalmente, para participar do mercado de trabalho. Porém, nas condições atuais, em que toda a sociedade vivencia uma era tecnológica, torna-se necessário também o domínio básico do computador.

Diante dessa situação, como nós, educadores, podemos contribuir para o aproveitamento dessa ferramenta? É possível superar antigos paradigmas e oportunizar um ensino de qualidade, fazendo uso dessa tecnologia?

Considerando que essas tecnologias estejam disponíveis a uma parcela considerável de usuários, há que se questionar: será que elas têm sido incorporadas em algumas ações dentro da sala de aula? E, em caso afirmativo, elas têm sido utilizadas de forma adequada?

Marques e Caetano (2002) argumentam que o uso da informática pode contribuir para auxiliar os professores em suas tarefas diárias, tanto para construir o conhecimento quanto para promover um ensino cada vez mais criativo, dinâmico; pode auxiliar nas descobertas, nas investigações, levando sempre em consideração a importância de promover o diálogo e as interações, principalmente entre os alunos e os professores.

Segundo Carneiro (2002), aos poucos, os sentimentos de resistência e de idolatria relativos às tecnologias mais recentes vão sendo substituídos por uma ação mais refletida e, à medida que essas tecnologias se tornam mais familiares e acessíveis, percebe-se que tanto a euforia quanto a resistência tendem a cegar e obscurecer a reflexão crítica necessária para tais avanços.

As palavras da autora conduzem ao seguinte questionamento: embora as tecnologias estejam sendo incorporadas no contexto escolar, será que essa incorporação tem sido feita de forma reflexiva? E a figura do computador, como tem sido percebida nos processos educativos? Entre as ferramentas que nele estão disponíveis, quais são as mais exploradas? Como fica o papel dos softwares? E o da internet?

Portanto, este artigo tem como objetivo fazer algumas discussões sobre o uso dos laboratórios de informática nas escolas públicas. Na primeira parte, faremos uma breve fundamentação teórica, juntamente com a apresentação de alguns softwares e, na sequência, apresentaremos os dados provenientes da pesquisa e os resultados e as discussões referentes aos dados provenientes deste trabalho. 


\section{Corpo teórico}

Atualmente é quase inevitável frequentarmos locais em que algum tipo de tecnologia esteja presente. Desde tempos remotos, o homem buscou construir ferramentas e objetos que lhe proporcionassem melhores condições para transformar a natureza e facilitar ações de seu cotidiano.

A própria história, conforme comentam Altoé e Silva (2005), registra que, desde a época da Pedra Lascada, os homens produziam instrumentos de pedra com o intuito de ajudá-los em suas atividades diárias, como coleta de alimentos, caça, pesca, etc. Havia também, desde aquela época, a necessidade de se comunicar com indivíduos do seu grupo, assim como também de outros grupos.

Desde então, o homem não parou de produzir instrumentos que pudessem ajudar a transformar sua vida e o meio que o cerca e também, de certa forma, auxiliá-lo em tarefas específicas. A esse respeito, assim afirmam Altoé e Silva (2005):

Ao conjunto de conhecimentos e princípios científicos que se aplica ao planejamento, à construção e à utilização de um equipamento em um determinado tipo de atividade nós chamamos de tecnologia. Portanto, para que os instrumentos possam ser construídos, o homem necessita pesquisar, planejar e criar tecnologias (Altoé; Silva, 2005, p.15).

Reportando-se aos dias atuais, Kenski (1996, p.128) argumenta que na atualidade, as alterações ocorridas a partir dos avanços da tecnologia invadem nosso cotidiano. As facilidades de comunicação e informação advindas dos avanços tecnológicos traduzem-se em mudanças irreversíveis nos comportamentos pessoais e sociais. Novas formas de pensar, de agir e de se relacionar comunicativamente são introduzidas como hábitos corriqueiros. A televisão, o rádio, o telefone, o videocassete são máquinas plenamente conhecidas por sujeitos de todas as camadas sociais.

A citação acima coloca em discussão a forma como a tecnologia tem se tornado irresistível para nós e, principalmente, como ela faz parte de nosso cotidiano.

É incrível o avanço que as tecnologias alcançaram nos últimos quinze anos. É claro que a TV e o rádio têm crescido neste período; no entanto, acreditamos que a informática é a grande protagonista deste processo de progresso e evolução tecnológica. Hoje, é espantosa a grande quantidade de 
informações que podem ser processadas nos celulares, que, de certa forma, não deixam de ser minicomputadores. A informação flui numa rapidez tão grande, que se tem a impressão de que os meios impressos se tornaram lentos. É aí que se percebe o quanto a internet se tornou popular, grandiosa e quase indispensável.

Quem já não ouviu falar de alguém que, em determinada ocasião, não conseguiu resolver algo, porque "o sistema estava fora do ar"? Os sistemas bancários, os sistemas de comunicação, os sistemas de controle de dados de uma escola, por exemplo, tudo é estruturado em torno de computadores.

E, é claro, esse dispositivo também faz parte do contexto escolar. Várias são as opiniões que defendem sua utilização nos processos de ensino.

$\mathrm{Na}$ visão de Baladeli, Barros e Altoé (2012, p. 56), a nova dinâmica proporcionada pelas tecnologias promove "o surgimento de novos paradigmas tanto de ensino quanto de aprendizagem".

Já, Carneiro (2002) salienta que o meio social em que o homem vive está cheio de recursos informatizados e tecnológicos, alguns tão interiorizados, que nem são mais lembrados ou considerados como tais, sendo, portanto, muito difícil estudar o homem e suas relações sociais, sem tê-los em conta.

É comum, também, ouvir falar sobre a resistência de alguns e a devoção de outros diante das tecnologias. O fato é que grande parte das escolas já compartilha dessas tecnologias, como é o caso das escolas do estado do Paraná: praticamente todas têm disponíveis laboratório de informática, TVs, pendrives em todas as salas, datashows, etc.

Carneiro (2002) ainda reforça seu ponto de vista, propondo a seguinte questão: "Até que ponto somos atores de nossos destinos quanto ao uso da tecnologia?"

O computador e a internet têm provocado grandes mudanças no cotidiano doméstico de crianças, jovens e adultos. A internet, os softwares e os jogos, dentre outros, passaram a ganhar espaço como instrumentos de entretenimento, de pesquisas e de trabalhos de escola. Com o uso de editores de textos, por exemplo, podem ser realizadas inúmeras atividades, como digitação, edição de imagens, inserção de imagens, tabelas, etc. Já, com as planilhas de cálculos, pode ser efetuada uma série de cálculos e montagem de gráficos e tabelas, dentre outras atividades. Não se pode deixar de citar, é claro, as enciclopédias virtuais e a variedade de sites que servem de fonte de pesquisas.

Marques e Caetano (2002) afirmam que a escola, ao incorporar os 
computadores, passará a ser um lugar mais atraente para os alunos, que não irão achar tanta diferença com as demais atividades sociais de que participam. Eles ainda apontam que é o fascínio com a novidade que se apresenta como desafio, fazendo com que o computador seja concebido como uma ferramenta útil no sistema de ensino-aprendizagem. Estes autores deixam claro que o cotidiano de muitos de nossos alunos está permeado de tecnologias, como é o caso do computador, e uma forma de diminuir esta diferença é, justamente, inseri-lo nas rotinas de atividades escolares.

\section{Softwares educacionais e o ensino de ciências}

Os softwares são programas desenvolvidos para várias funções, dentre elas auxiliar em atividades educativas e no ensino. Eles podem ser considerados como programas educacionais, a partir do momento que sejam projetados por meio da colaboração de profissionais de várias áreas e que realmente contextualizem os processos de ensino e aprendizagem. Mas de nada adianta um bom software, se não houver professores que queiram utilizá-los e estejam preparados para o uso desse recurso.

Já os softwares livres, segundo Aguiar (2009), são aqueles que surgiram a partir da década de 1980. E, para Silveira (2004), seus maiores defensores são os hackers, muitos acadêmicos, alguns cientistas e, mais recentemente, as forças político-culturais que, de certa forma, apoiam a distribuição dos benefícios nesta conhecida era da informação. Já as grandes empresas que comercializam programas de informática são suas maiores opositoras, pois, baseadas em fatores econômicos, procuram apenas arrecadar dinheiro (por meio das licenças de uso de softwarese do controle monopolizador dos códigos, que são essenciais para o funcionamento dos programas de computador) - em outras palavras, visam apenas ao lucro.

Embora haja esse grande combate, em que, de um lado, temos alguns intelectuais que defendem a distribuição gratuita desses programas, com o intuito de difundir o conhecimento, e, do outro, empresas que buscam apenas lucros, com a pretensão de aumentar seu giro econômico e a ampliação de seu capital, muitos softwares conseguem sobreviver a essa disputa.

A Biologia, a Física, a Química e a Matemática são algumas das disciplinas que lideram o ranking de reprovações de alunos em todo Brasil. Não diferentemente de outras disciplinas, acreditamos que possam vir a melhorar substancialmente com o uso de tecnologias inovadoras. É um recurso adicional 
que pode contribuir significativamente para tornar as aulas mais dinâmicas.

Gianoto (2008) salienta que, considerando os problemas relacionados aos processos de ensino e aprendizagem, que levam muitos professores à desmotivação, o ensino de Ciências - Biologia, Física e Química - tornou-se objeto de discussões, o que fez despertar um interesse maior de professores e pesquisadores na área de educação, que procuram identificar e analisar as características e as tendências que têm norteado o ensino de Ciências.

Gianoto (2008, p. 27) acrescenta:

Acredita-se que o interesse, no aprofundamento das questões relativas ao ensino desta área, esteja ligado aos desafios enfrentados pelos educadores, pois no Brasil o ensino das Ciências Físicas, Químicas e Biológicas tem sofrido grandes transformações, ocasionadas por vários fatores, entre os quais o reconhecimento da Ciência e da Tecnologia como elementos essenciais no desenvolvimento econômico, cultural e social.

Assim, de acordo com a autora, a tecnologia é um dos fatores que têm contribuído para repensar o Ensino de Ciências. Essa tecnologia nos remete diretamente, dentre outros recursos, ao computador.

Valente (1999) afirma que o computador pode ser uma importante ferramenta, capaz de promover a passagem da informação ao usuário ou facilitar o processo de construção do conhecimento. Ele ainda argumenta que, por intermédio da análise dos softwares, é possível compreender que o aprender (memorização ou construção do conhecimento) não deve estar restrito ao software, mas depende da interação do aluno com ele. Assim como no caso da internet, é necessário que o professor planeje suas atividades com antecedência, para propiciar uma situação que permita que os alunos realmente interajam com os softwares.

Valente (1999) ainda complementa: "como foi mostrado por Piaget, o nível de compreensão está relacionado com o nível de interação que o aprendiz tem com o objeto e não com o objeto em si".

Como qualquer outro recurso didático, não desejamos que o software seja utilizado em todas as aulas, mas em momentos apropriados, tendo o professor a liberdade de alternar os diferentes recursos, dependendo dos objetivos a serem abordados em cada aula.

Melo e Antunes (2002, p. 65) afirmam que "as escolas devem incentivar 
e aderir à filosofia do software livre ${ }^{5}$ e promoverem um intercâmbio de programas e experiências em busca de um melhor aprendizado".

Percebemos, então, que o software não funciona como um objeto "inerte". Com essa afirmação, procuramos, de certo modo, admitir que seja possível estabelecer relações entre a máquina e o aluno. Para Piaget (1980), o processo de desenvolvimento da criança depende de fatores ligados à sua experiência, adquirida pelo contato com o meio. Davis e Oliveira (1994) argumentam que, no processo de conhecimento, é preciso considerar a presença do sujeito (alguém que conhece) e de algo a ser conhecido, o objeto. Entre o objeto de conhecimento e o sujeito são estabelecidas relações que requerem um elemento mediador. O software pode representar, em determinadas situações, o elemento mediador entre o sujeito (aluno) e o objeto (conhecimento). Portanto, o professor de Ciências e Matemática, com o devido preparo, poderá usar os softwares sempre que julgar necessário, em suas atividades educativas, uma vez que, a partir deles, é possível criar situações que envolvam a aprendizagem.

Passaremos, na sequência, a apresentar alguns softwares que podem ser utilizados em alguns momentos em disciplinas como Física e Matemática e algumas de suas funções.

I) ESTELLARIUM: É um software livre, de astronomia, na forma de um planetário, para visualizar o céu. Ele possui uma ótima qualidade técnica e gráfica, podendo simular o céu diurno e o noturno, assim como seus crepúsculos, de forma bem realista. Ele ainda faz a simulação de planetas, luas, estrelas e eclipses em tempo real, fornecendo informações detalhadas de milhares de corpos celestes.

II) CELESTIA: É um programa também livre, em 3D (três dimensões), sobre astronomia, e funciona tanto no Windows quanto no Linux. Permite que o usuário visualize objetos, variando em escala de satélites artificiais e galáxias inteiras em 3D. Diferentemente de outros programas para planetários, oferece ao usuário a liberdade de viajar através do universo.

Figura 1: Visualização de constelações por meio do Stellarium

${ }^{5}$ Softwares para cuja utilização não é preciso pagar licença, ou seja, são gratuitos.

Zetetiké - FE/Unicamp - v. 22, n. 42 - jul/dez-2014 


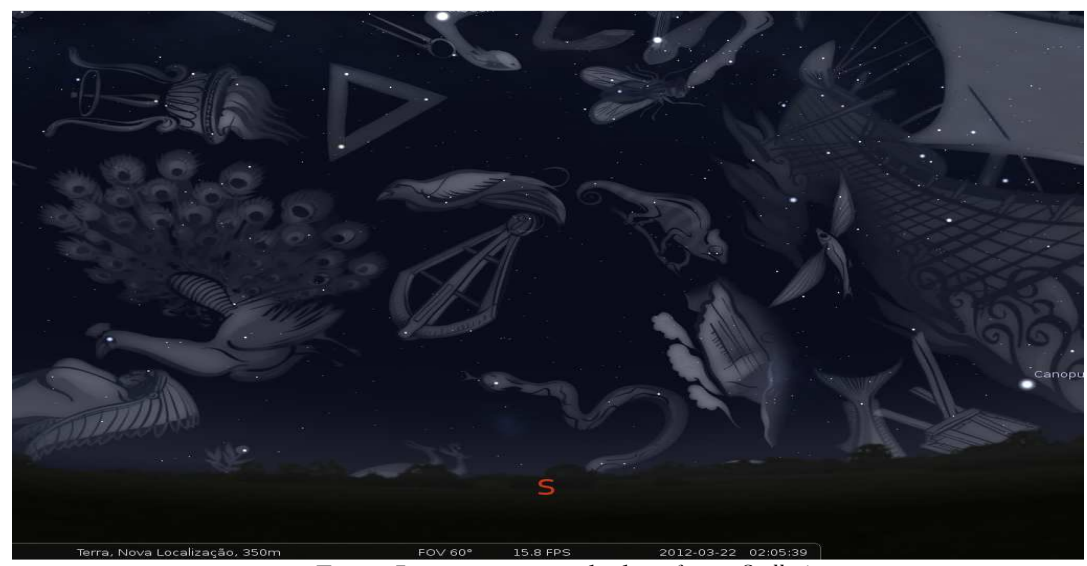

Fonte: Imagem capturada do software Stellarium

Figura 2: Visualização do planeta Saturno por meio do Celestia

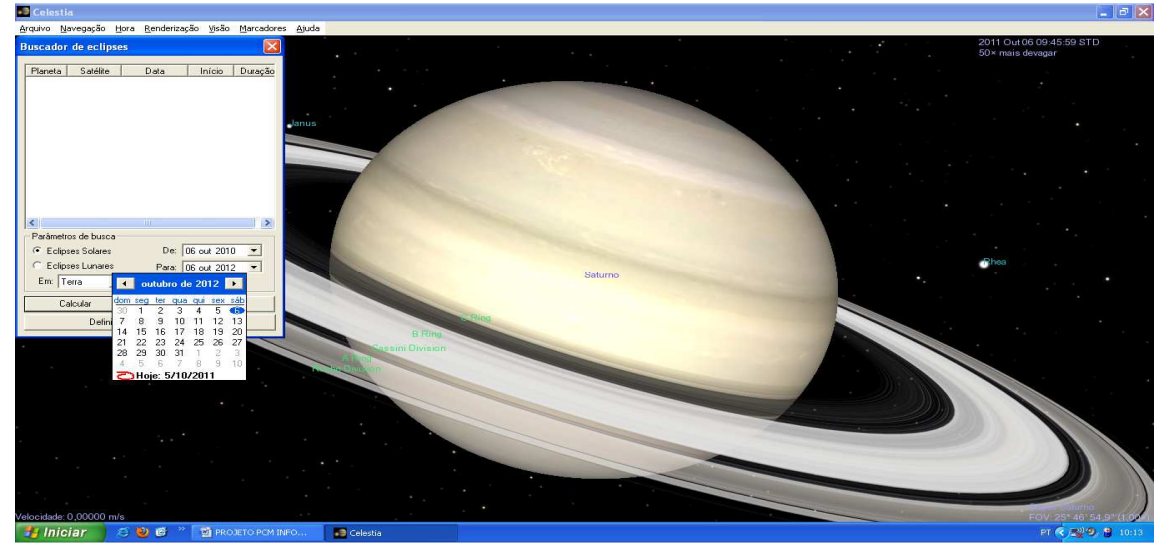

Fonte: Imagem capturada do software Celestia

Estes softwares podem contribuir para a dinamização das aulas, promovendo maior ludicidade nos processos que envolvem o ensino - no caso, o de conhecimentos e conceitos de astronomia -, buscando, assim, proporcionar uma aprendizagem mais prazerosa e, consequentemente, significativa. Devido a sua rica interface gráfica, softwares como os citados podem contribuir para a compreensão de vários significados ligados à astronomia, devido às inúmeras simulações que com eles podem ser efetuadas. 
Desse modo, tais ferramentas poderão proporcionar bons resultados, uma vez que não necessitam da alta abstração que alguns métodos tradicionais requerem, em que o professor é o detentor do saber e o conhecimento geralmente é visto apenas como aquele presente nos livros didáticos.

III) GEOGEBRA: É um programa de Matemática dinâmica, para uso em sala de aula, que relaciona aritmética, álgebra, geometria e cálculo. O Geogebra possibilita o desenho de pontos, vetores, segmentos, linhas e funções, além da alteração dinâmica entre eles.

IV) SIMETRIA: Este software permite explorar transformações no plano, como reflexão, rotação e translação. Permite ainda que se construam rosetas, frisos e papéis de parede.

Figura 3: Visualização/construção de cônica por meio do Geogebra

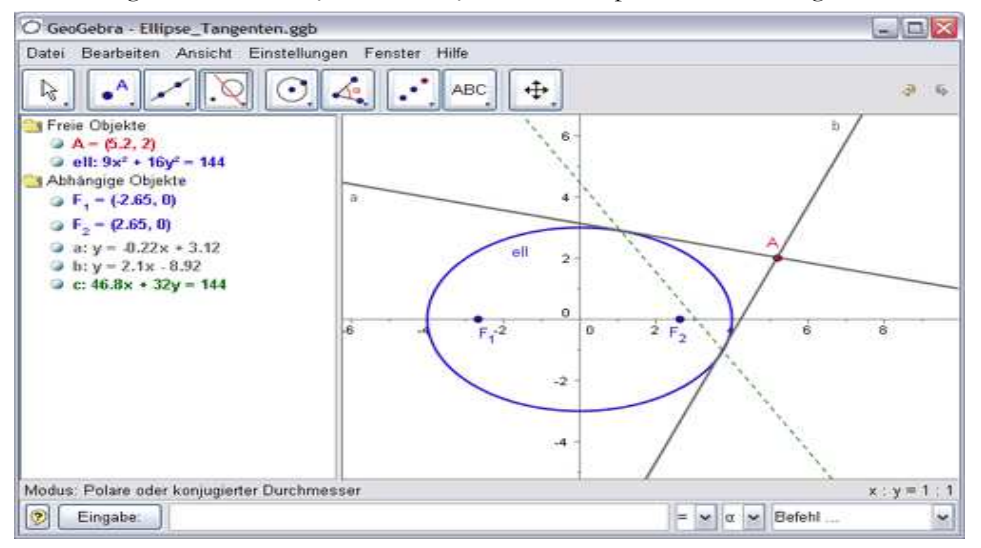

Fonte: Imagem capturada do software Geogebra 
Figura 4: Visualização/construção de figura simétrica

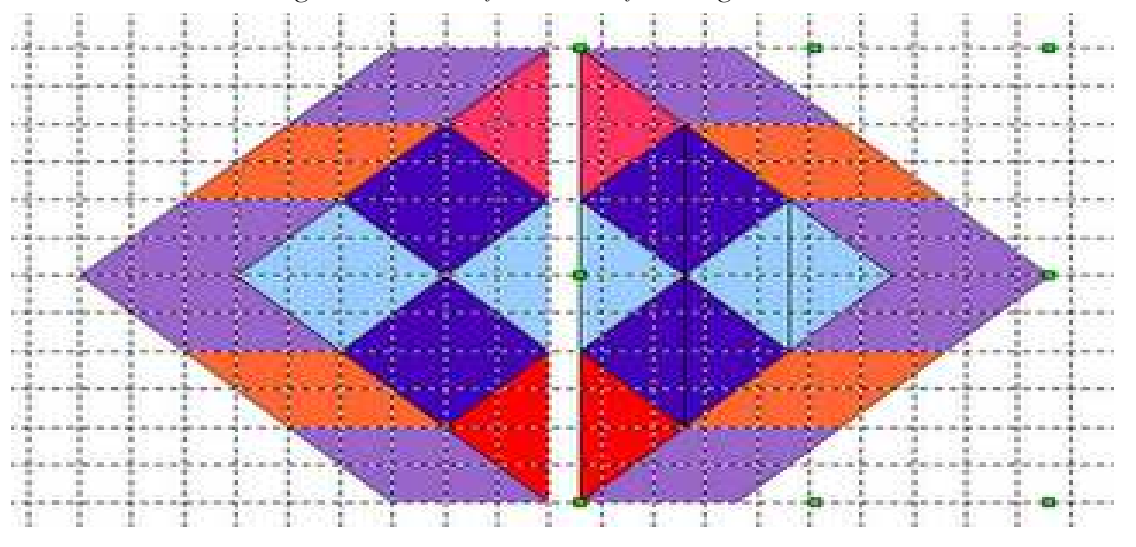

Fonte: Imagem capturada do software simetria

Estes são meros exemplos de muitos conceitos e conteúdos a serem ser explorados, utilizando-se softwares. Há inúmeros programas gratuitos que podem ser utilizados como ferramenta nos processos de ensino e aprendizagem de todas as disciplinas. É importante destacar que todos os softwares mencionados aqui são compatíveis com o sistema operacional Linux, presente nas escolas onde ocorreu a investigação.

\section{Os softwares e as imagens}

Santaella (2003) afirma que, durante o século XX, houve o crescimento de duas ciências da linguagem, sendo uma delas a Linguística, ciência da linguagem verbal, e a outra, a Semiótica, ciência de toda e qualquer linguagem. Portanto, como este trabalho aborda, dentre outras questões, as imagens, serão discutidos brevemente alguns eixos básicos que norteiam a Semiótica ${ }^{6}$.

O homem, desde tempos remotos, buscou maneiras de se expressar por meio de gestos, palavras, sinais, símbolos, desenhos, etc. Algumas cavernas ao redor do mundo servem até hoje como testemunho e fonte de registros de sua arte de se expressar. Esse modo particular de linguagem tinha como objeto principal a imagem. Platão foi um dos primeiros homens a definir o que seria

${ }^{6}$ A linha de Semiótica abordada neste trabalho refere-se ao trabalho de Charles Sandres Peirce (18391914). Parte de seu legado pode ser verificado na obra O que é Semiótica, de Lúcia Santaella (2003). 
uma imagem - "chamo de imagens em primeiro lugar as sombras, depois os reflexos que vemos nas águas ou na superfície de corpos opacos, polidos e brilhantes e todas as representações do gênero" (Joly, 1996, p. 14). Desde então, conforme afirma a mesma autora, percebemos que a imagem seria um objeto segundo, com relação a outro que ela representaria, de acordo com determinadas leis específicas e particulares.

A imagem, portanto, seria "algo" que pretende representar "algo". Podemos ter uma rápida noção disso, quando, por exemplo, estamos dirigindo numa cidade e, ao depararmos com um cruzamento cujo sinal esteja vermelho, intuitivamente sabemos que devemos parar. Para isso, entretanto, recorremos a um "signo", a luz vermelha. De acordo com Santaella (2003), há várias definições para signo e, dentre elas, ela afirma que um signo intenta representar, em parte pelo menos, um objeto que é, portanto, em determinado sentido, a causa ou o determinante do signo, mesmo se este representar seu objeto falsamente.

Ela ainda acrescenta:

[...] mas dizer que ele representa seu objeto implica que ele afete uma mente, de tal modo que, de certa maneira, determine naquela mente algo que é mediatamente devido ao objeto. Essa determinação da qual a causa imediata ou determinante é o signo, e da qual a causa mediata é o objeto, pode o ser chamada de interpretante (Santaella, 2003, p. 12).

Em síntese, signo é "algo" que representa outro "algo", um objeto. Santaella (2003) conclui que ele (o signo) só poderá de fato funcionar como tal, se carregar esse poder de representar, substituir uma outra coisa diferente dele.

Não diferente disso, Joly (1996) afirma que o conceito de signo é antigo e designa algo que se percebe, como as cores, as formas, o calor, os sons, e a que se dá uma significação. O signo pode constituir um ato de comunicação, por isso fazemos, no Esquema 1, uma representação gráfica dos signos.

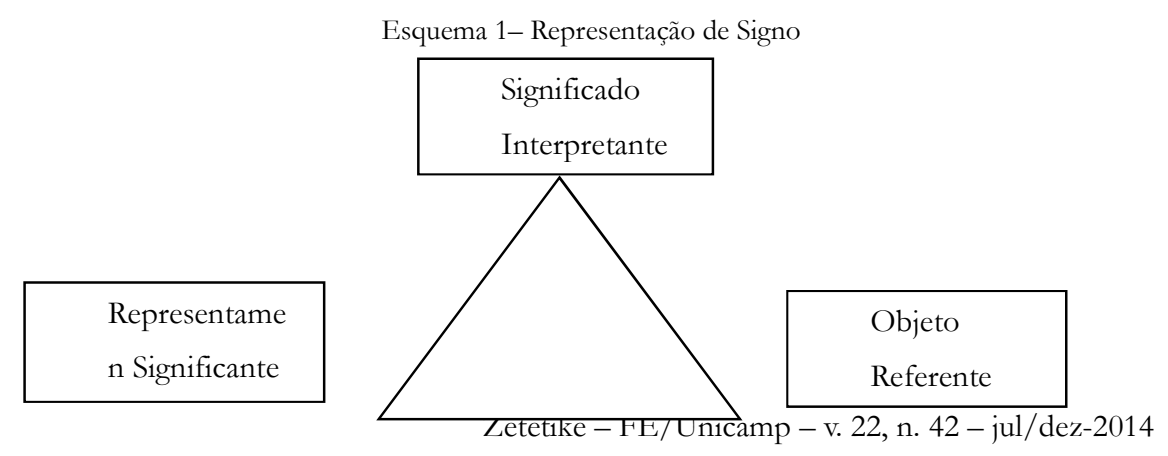


Fonte: adaptado de Joly (1996)

Essa representação demonstra que o signo mantém uma relação entre, pelo menos, três polos: a face perceptível do signo, representada no gráfico como representamen ou significante, é aquilo que realmente é perceptível por nós; o objeto ou referente é exatamente o que ele representa; e, por último, o significado ou interpretante nada mais é do que aquilo que ele significa.

Para Joly (1996), essa triangulação também pode representar a dinâmica de qualquer signo como processo semiótico, cuja significação dependerá do contexto de seu aparecimento, assim como também da expectativa de seu receptor. As imagens, desse modo, podem conter muito mais significados do que podemos imaginar. Coll, Engel e Bustos (2010) salientam que certos ambientes virtuais envolvem aspectos de aprendizagem baseados na representação visual do conhecimento. Eles complementam:

Os sistemas de representação sempre foram utilizados nos processos de ensino e aprendizagem. Podemos encontrá-los nos livros didáticos de todos os níveis educacionais, da educação infantil ao ensino superior; nos mapas, cartazes e murais que enfeitam as salas de aula; nos gráficos, croquis, diagramas e outros tipos de esquemas que os professores desenham no quadro; ou, ainda, nos slides e vídeos que às vezes são utilizados para mostrar processos complexos e abstratos (Coll; Engel; Bustos, 2010, p. 226).

Os mesmos autores também argumentam que o atual desenvolvimento tecnológico proporcionou a criação de materiais midiáticos, como as animações, que abriram novas interrogações sobre os efeitos das representações visuais nos processos que envolvem ensino e aprendizagem.

\section{Metodologia}

Ao propormos desenvolver este estudo sobre utilização da informática e softwares para ensinar, o local escolhido como ambiente de pesquisa foi o próprio laboratório de informática, onde, por meio de ações, reflexões, foram desenvolvidas as atividades necessárias não somente para coleta de dados, mas para a efetiva interpretação deles.

Esta pesquisa se classifica como qualitativa, e Mazzoti e Gewandsznajder (1998) têm como uma das características mais marcantes desse tipo de estudo 
a utilização do ambiente natural como fonte de dados, sendo o pesquisador aquele que desempenha o papel do principal instrumento.

Existem, em média, 2.200 escolas estaduais no Paraná, e, de acordo com a SEED, em todas elas há, no mínimo, um laboratório de informática. Nesse sentido, foi feito um levantamento sobre o uso dos laboratórios de informática em duas escolas estaduais - denominadas, aqui, com as letras A e B - no município paranaense de Barbosa Ferraz.

A escola A, com aproximadamente 850 alunos matriculados, oferta desde o Ensino Fundamental até o Ensino Profissionalizante, funcionando em três turnos diários: matutino e vespertino, com Ensino Fundamental e Médio; e período noturno, com a oferta de Ensino Médio e Educação Profissional. Já a escola B, além do Ensino Fundamental e Médio, também oferta o Ensino de Jovens e Adultos - EJA - e tem, aproximadamente, 700 alunos matriculados. Ela também funciona em três períodos diários: matutino e vespertino, com Ensino Fundamental e Médio; e noturno, com o Ensino de Jovens e Adultos. Em cada uma das escolas atuam aproximadamente 70 professores. Como no período noturno as escolas diferem na modalidade de ensino que ofertam, a pesquisa levou em consideração os dados obtidos nos períodos matutinos e vespertinos de ambas as escolas. A questão problema aqui contemplada, foi exatamente verificar se os softwares são utilizados nos laboratórios de informática nas referidas escolas.

O sistema operacional dos computadores que fazem parte dos laboratórios de informática de ambas as escolas é o Linux. A diferença mais marcante entre Linux e Windows é o fato de o Linux ser um sistema que pode ser instalado gratuitamente, enquanto o Windows é software cuja licença precisa ser comprada para ter o direito de usá-lo.

Em cada uma das escolas mencionadas há aproximadamente 30 computadores. A pesquisa consistiu em verificar a frequência com que o laboratório de informática é utilizado e, principalmente, que recursos são os mais usados. Os referidos dados correspondem à utilização do laboratório de informática das referidas escolas durante o mês de agosto de 2012. Como em cada turno são oferecidas 5 horas-aula diárias, ao final da semana somam-se 25 horas-aula e, consequentemente, em um mês disponibilizam-se, em cada escola, aproximadamente 100 horas-aulas para que os professores agendem suas atividades nos laboratórios de informática. 


\section{Resultados e discussões}

Tanto na escola A quanto na escola B, utilizou-se o laboratório nos turnos da manhã e da tarde, levando em consideração o número total de horasaulas disponíveis em um mês, como mostram a Tabela 1 e o Gráfico1:

Zetetiké - FE/Unicamp - v. 22, n. 42 - jul/dez-2014 
Tabela 1 - Utilização dos Laboratórios de Informática por Turno

\begin{tabular}{l|l|l}
\hline Escola & $\begin{array}{l}\text { Período matutino } \\
\text { (aprox. 100 h/a mês) }\end{array}$ & $\begin{array}{l}\text { Período vespertino } \\
\text { (aprox. 100 h/a mês) }\end{array}$ \\
\hline A & 64 & 46 \\
\hline B & 36 & 28 \\
\hline
\end{tabular}

Fonte: Dados obtidos nos livros de controles e agendamento dos laboratórios de informática das escolas A e B, 2012.

Gráfico 1 - Utilização dos Laboratórios de Informática - Escolas A e B

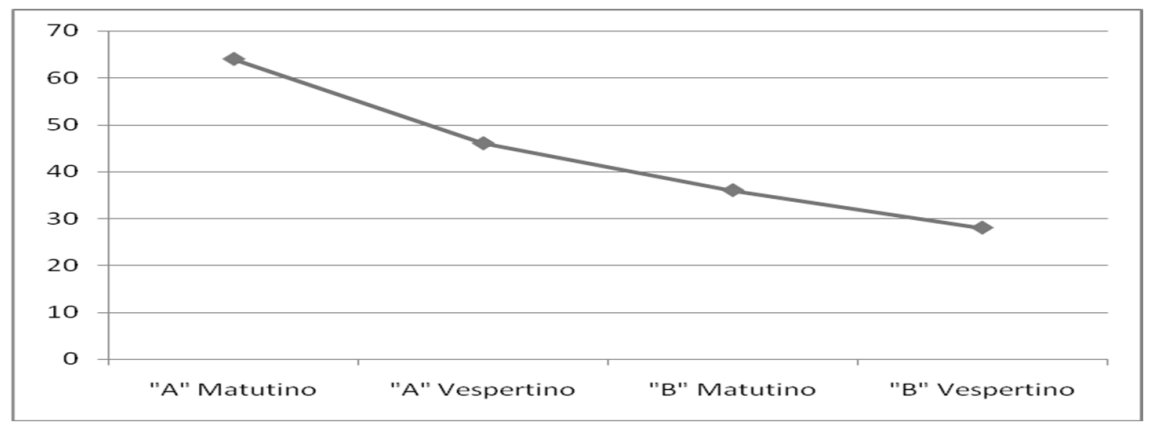

Fonte: Dados obtidos nos livros de controles e agendamento dos laboratórios de informática das escolas A e B, 2012.

De acordo com os dados, em termos de comparação, a escola A utiliza o laboratório com mais frequência do que a escola $\mathrm{B}$, em ambos os turnos. Fica claro também que o laboratório de informática é um local que os professores têm utilizado frequentemente, principalmente na escola $\mathrm{A}$.

Embora haja uma diferença razoável entre as escolas A e B, quanto à utilização dos laboratórios, ambas apresentam bons números, quanto ao uso do laboratório. Isso mostra que, de certa forma, esses espaços vêm sendo usados. Mas, ao trabalhar nesses laboratórios, quais recursos são os mais utilizados? Nas Tabelas 2 e 3 temos dados que indicam quais tipos de recursos foram utilizados juntamente com o computador. 
Tabela 2 - Recursos utilizados no Período Matutino

\begin{tabular}{l|c|c|c}
\hline Escola & \multicolumn{2}{|c}{ Recursos Utilizados } \\
\hline & Internet & Softwares & Outros \\
\hline A & 62 & 2 & 0 \\
\hline B & 30 & 0 & 2 \\
\hline
\end{tabular}

Fonte: Dados obtidos nos livros de controles e agendamento dos laboratórios de informática das escolas A e B, 2012.

Tabela 3 - Recursos utilizados no Período Vespertino

\begin{tabular}{c|c|c|c}
\hline Escola & \multicolumn{2}{|c}{ Recursos Utilizados } \\
\hline & Internet & Softwares & Outros \\
\hline A & 46 & 0 & 0 \\
\hline B & 28 & 0 & 0 \\
\hline
\end{tabular}

Fonte: Fonte: Dados obtidos nos livros de controles e agendamento dos laboratórios de informática das escolas A e B, 2012.

Os números mostram nitidamente que o recurso explorado nos laboratórios de informática, nas escolas pesquisadas, é basicamente a internet, ou seja, os alunos se limitam a pesquisas on-line. Não queremos, aqui, criticar a utilização da internet; pelo contrário, acreditamos que ela é uma ferramenta poderosa, quando utilizada de forma adequada. No entanto, consideramos que o computador é um recurso que possui várias ferramentas que poderiam contribuir para o aprendizado em muitas disciplinas. Por isso, fazer uso do laboratório de informática apenas para realizar pesquisas em sites faz com que o computador perca muito de seu potencial.

Carneiro (2002) afirma que muitos professores que utilizam o computador com alguma frequência em suas aulas percebem que esse aparelho, quando utilizado de forma contextualizada, pode ajudar na resolução de situações problemas e em atividades de aprendizagem. A autora reforça que a contextualização do computador e de seus múltiplos objetos é importante para contribuir em processos que envolvem a aprendizagem.

A partir dos dados coletados, foi possível escrever o percentual de aulas realizadas no laboratório de informática, que utilizam algum recurso além da internet, como mostram as tabelas 4 e 5 . 
Zetetiké - FE/Unicamp - v. 22, n. 42 - jul/dez-2014 
Tabela 4 - Percentual de Recursos Utilizados no Período Matutino

\begin{tabular}{c|c|c|c}
\hline Escola & \multicolumn{2}{|c}{ Recursos Utilizados } \\
\hline & Internet & Softwares & Outros $^{7}$ \\
\hline$\% \mathrm{~A}$ & 96,77 & 3,23 & 0 \\
\hline$\% \mathrm{~B}$ & 93,34 & 0 & 6,66 \\
\hline
\end{tabular}

Fonte: Fonte: Dados obtidos nos livros de controles e agendamento dos laboratórios de informática das escolas A e B, 2012.

Tabela 5 - Percentual de Recursos Utilizados no Período Vespertino

\begin{tabular}{c|c|c|c}
\hline Escola & \multicolumn{2}{|c}{ Recursos Utilizados } \\
\hline & Internet & Softwares & Outros \\
\hline$\% \mathrm{~A}$ & 100 & 0 & 0 \\
\hline$\% \mathrm{~B}$ & 100 & 0 & 0 \\
\hline
\end{tabular}

Fonte: Dados obtidos nos livros de controles e agendamento dos laboratórios de informática das escolas A e B, 2012.

Diante dos percentuais mostrados nas tabelas, vemos que os laboratórios de informática, nas referidas escolas, são usados quase exclusivamente para acessar a internet e fazer pesquisas on-line. A utilização de softwares e de outros recursos representa um percentual muito pequeno, que deveria ser maior. Para Guimarães et al. (2010), a internet traz informações a espaços que jamais teriam acesso a elas, rompe barreiras que interferem na comunicação. No entanto, o trabalho pedagógico precisa estar inserido numa prática de construção de conhecimento, para ser mais eficaz.

Mercado (2002, p. 160), por sua vez, afirma que,

[...] para que as atividades pedagógicas baseadas na internet sejam possíveis, deve-se solicitar aos professores requisitos como: empenho a longo prazo, ultrapassar obstáculos técnicos e assimilar uma série de informações; adquirir cultura tecnológica, para se tornar assistente da construção do conhecimento através desta tecnologia.

O autor, ao fazer essa afirmação, nos leva a refletir que as "atividades

${ }^{7} \mathrm{O}$ item "Outros", apresentado nas tabelas deste trabalho, refere-se à utilização integrada do laboratório de informática e do datashow. 
pedagógicas" descritas por ele não se limitam apenas a "pesquisas", mas, sim, permitem uma maior interação entre o aluno e o objeto explorado por ele. É claro que, para isso, é necessário preparo, e Mercado (2002) deixa isso bem evidente, quando expressa "adquirir uma cultura tecnológica", ou seja, é necessário que os professores passem a utilizar com mais frequência recursos tecnológicos, como o computador e softwares de informática.

Certamente, algumas tecnologias estão presentes no seio de nossas escolas, especialmente, como já citado, nos laboratórios de informática. No entanto, pela pesquisa ali realizada, vemos que o uso do computador tem se resumido meramente a pesquisas na internet.

Diante disso, é necessário que se criem e ampliem as políticas públicas voltadas para a capacitação dos professores, para que eles tenham maiores condições de explorar e, consequentemente, utilizar com seus alunos outros recursos, além da internet.

Almeida (2000) argumenta que as práticas pedagógicas de utilização dos computadores se estruturam em duas abordagens: a instrucionista e a construtivista. Desse modo, como o professor que "não domina" o computador em um nível satisfatório poderá utilizá-lo em atividades que realmente proporcionem ambientes de aprendizagem?

De acordo com a constatação propiciada pelos dados, percebemos que dificilmente, ao utilizar o laboratório de informática, os docentes conseguirão desenvolver uma abordagem construtivista, se não possuírem o mínimo domínio do computador. É fato também que a informática, principalmente nos últimos anos, tem se configurado como uma ferramenta consideravelmente poderosa, quando empregada na educação.

Para Nogai (2005, p. 33),

[...] a informática na educação é vista como uma nova e promissora área a ser explorada e com potencial que pode possibilitar mudanças nos sistemas educacionais. Por isso, a importância que se reveste a formação de professores no domínio da tecnologia para que se tornem capazes de refletir e de participar ativamente desse processo de mudança da inserção da informática aplicada à educação.

A utilização de tecnologias, como o computador, é uma forma de ampliar as possibilidades de sucesso em processos que envolvem ensino e aprendizagem, e é também um recurso para promover formas diferentes daquelas mais convencionais. Todavia, para isso, é fundamental a formação dos 
professores.

Valente (1999) argumenta que muitos cursos que buscam proporcionar certa formação em informática são realizados em ambientes bem diferentes daqueles que compõem o cotidiano do professor, com um foco bem distinto do encontrado em sala de aula. Sem falar que, em muitos casos, o sistema operacional também é diferente: Windows nos cursos x Linux nas escolas.

Nesse sentido, o autor acrescenta que

[...] um curso de formação de professores em informática na educação, embasada na proposta construcionista-contextualizada, significa um curso fortemente baseado no uso do computador, realizado na escola onde esses professores atuam, criando condições para os professores aplicarem os conhecimentos com os alunos, como parte do processo de formação. Isso implica em propiciar as condições para o professor agir, refletir e depurar o seu conhecimento em todas as fases pelas quais ele deverá passar na implantação do computador na sua prática de sala de aula: dominar o computador (software e hardware) (Valente, 1999, p. 141).

Nas palavras do autor, para haver uma efetiva "formação em informática" com intuito educativo, o professor requer um ambiente propício, ou seja, é preciso realizar todas as etapas de sua formação, levando em consideração a sua realidade escolar e, principalmente, suas reais necessidades.

Fugimoto (2010), ao argumentar a favor da utilização do computador como ferramenta educacional, salienta que o professor necessita de uma formação que possa capacitá-lo para o desenvolvimento de atividades que contribuam para a construção de conhecimentos dos alunos.

Já, Coll e Illera (2010) argumentam pela necessidade de os educadores aprenderem muito mais do que manusear a máquina, o computador. Os autores sugerem o que denominam "alfabetização digital", ou seja, uma formação que se associe às tecnologias digitais da informação e da comunicação relacionadas com a sociedade da informação.

Vemos que a formação do professor, quanto à temática tecnológica, especialmente no caso do objeto de estudo desta pesquisa (computadorsoftwares), vai além do simples domínio de teclas e ferramentas que compõem o material tecnológico. Portanto, é indispensável que o educador, tido como mediador de processos que envolvem a construção do conhecimento, saiba promover a construção de elementos que acentuem a importância e a utilização dessa tecnologia em nossa sociedade. É ele também que deverá contribuir para 
a construção da consciência de que as TICs podem assumir importantes papéis como recursos didático-metodológicos, capazes de produzir resultados significativos, como os apontados nesta pesquisa.

É importante atentar a essas questões, uma vez que, diferentemente de anos anteriores, o estado do Paraná, por meio do edital Seap 017/2013, abriu, em janeiro de 2013, concurso público para contratação de professores e pedagogos para atuarem na rede básica. O interessante é que o edital previa, além de prova de conhecimentos específicos de cada área e de fundamentos da educação, a realização de uma prova de conhecimentos gerais, contemplando conhecimentos de informática, conforme pode ser verificado no Anexo III do referido edital.

\section{Considerações finais}

Durante as discussões apresentadas, percebemos que, desde muito tempo, o homem tem elaborado tecnologias com o intuito de contribuir com suas ações diárias. Até que se atingisse o patamar tecnológico que hoje se alcança, foi necessário aplicar muita determinação, empenho e vontade de avançar e obter progresso. A ciência, em especial, contribui sobremaneira para tais transformações e, embora nem todos tenham acesso à parte mínima de algumas das referidas tecnologias, por certo, um grande passo já foi dado em direção às transformações das realidades cotidianas, inclusive a escola considerando essa localização geográfica -, uma vez que milhões de pessoas ao redor do mundo têm, mesmo nos dias de hoje, pouco contato com tecnologias como o computador.

Ao longo desta pesquisa, vários foram os autores citados que salientam a importância de considerar o uso de recursos como os computacionais no âmbito escolar ou que destacam a importância da formação inicial e continuada de professores com relação a esta temática.

Entretanto, com base nas informações obtidas, percebemos que tecnologias (como o computador) são ferramentas disponíveis no seio de muitas escolas, como no caso estudado. Porém, os dados evidenciaram que a utilização nas referidas escolas tem se resumido meramente a pesquisas na internet.

Esses professores de Ciências já se depararam algumas vezes com certas situações que julgamos inquietantes, em que tivemos a impressão de que apenas nossa argumentação não era o bastante para explicitar o que gostaríamos de

$$
\text { Zetetiké - FE/Unicamp - v. 22, n. } 42 \text { - jul/dez-2014 }
$$


mostrar. Em outras palavras, não conseguimos demonstrar apenas por meio de palavras aquilo que pretendíamos, ou seja, apenas palavras não pareciam suficientes para ilustrar o que se objetivava. Evidenciou-se, por conseguinte, a necessidade de utilizar algum recurso que pudesse "ilustrar" de forma mais "clara" os conceitos que tentávamos explicar.

Obviamente, a utilização de um recurso como uma imagem, um vídeo, um som, um software, nem sempre é possível; entretanto, às vezes, quando bem empregados, esses recursos são capazes de potencializar e ampliar as possibilidades de obter resultados significativos nos processos que envolvem o ensino e a aprendizagem.

As informações e os resultados discutidos na presente pesquisa revelaram que tecnologias como o computador e os softwares que nele podem ser executados assumem o papel de recurso didático-metodológico, uma vez que foram capazes de exprimir, por meio de imagens, conceitos que, se fossem transmitidos apenas de forma oral, não teriam o mesmo resultado nos processos de ensino e aprendizagem. No entanto, atividades com as referidas ferramentas demandam formação e capacitação.

Diante disso, acreditamos que é necessário que se criem e ampliem as políticas públicas voltadas para a capacitação dos professores, para que eles tenham maiores condições de explorar e, consequentemente, de utilizar, juntamente com os alunos, outros recursos além da internet, como por exemplo, os softwares de simulações.

É necessário também que o professor tenha a consciência de que não é a simples introdução do computador na escola que proporcionará mudanças dos processos de aprendizagem dos alunos, pois ele é uma ferramenta que precisa ser explorada e usada adequadamente, para produzir bons resultados.

Sendo assim, esperamos que estas novas tecnologias ao alcance dos professores e dos alunos possam ser utilizadas para contribuir ainda mais para o êxito das atividades escolares, assim como para melhorar aspectos relacionados à construção do conhecimento de disciplinas como a Matemática e a Física, além das demais áreas de ensino. Entretanto, é necessário que os educadores, independentemente do nível de ensino em que atuem, olhem essa tecnologia dentro de uma perspectivamais otimista, buscando, com isso, melhorar suas aulas e contribuir para uma educação que seja, ao mesmo tempo, científica e tecnológica, algo que nos dias atuais é quase indispensável.

Zetetiké - FE/Unicamp - v. 22, n. 42 - jul/dez-2014 


\section{Referências}

AGUIAR, V. M. (Org.). Software livre, cultura hacker e ecossistema da colaboração. São Paulo: Momento Editorial, 2009.

ALMEIDA, M. E. Informática e a formação de professores. Brasília: MEC, 2000.

ALTOÉ, A.; SILVA, H. O desenvolvimento histórico das novas tecnologias e seu emprego na Educação. In: ALTOÉ, A.; COSTA, M. L. F.; TERUYA, T. K. Educação e novas tecnologias. Maringá: Eduem, 2005. p. 13-25.

BALADELI, A. P. D.; BARROS, M. S. F.; ALTOÉ, A. Desafios para o professor na sociedade da informação. Educar em Revista, Curitiba, n. 45, p.155-165, jul./set. 2012.

CARNEIRO, R. Informática na educação - representações sociais no cotidiano. São Paulo: Cortez, 2002.

COLL, C.; ENGEL, A.; BUSTOS, A. Os ambientes virtuais de aprendizagem baseados na representação visual do conhecimento. In: COLL, C., MONEREO, C. (Org.). Psicologia da educação virtual - aprender e ensinar com as tecnologias da educação e da comunicação. Porto Alegre: Artmed, 2010. cap. 11, p. 226-244.

COLL, C.; ILLERA, J. L. R. Alfabetização, novas alfabetizações e alfabetização digital. In: COLL, C.; MONEREO, C. (Org.). Psicologia da educação virtual - aprender e ensinar com as tecnologias da educação e da comunicação. Porto Alegre: Artmed, 2010. cap. 14, p. 287-310. DAVIS, C.; OLIVEIRA, Z. M. R. Psicologia na educação. 2. ed. São Paulo: Cortez, 1994. FOLHA ON-LINE (2013). Acesso à internet no Brasil cresce, mas 53\% da população ainda não usa a rede (15 maio 2013). Disponível em: http://www1.folha.uol.com.br/mercado/2013/05/1279552-acesso-a-internet-no-brasilcresce-mas-53-da-populacao-ainda-nao-usa-a-rede.shtml. Acesso em: 07 dez. 2014

FUGIMOTO, S. M. A. O computador na sala de aula: o professor de educação básica e sua prática pedagógica. 2010. 143 fls. Dissertação (Mestrado em Educação) - Universidade Estadual de Maringá, Maringá, 2010.

GIANOTTO, D. E. P. Formação inicial de professores de biologia: análise de uma proposta de prática colaborativa com o uso de computadores. 2008. 289 p. Tese (Doutorado em Educação para a Ciência) - Faculdade de Ciências, Unesp, Bauru.

GUIMARÃES, G. R. et al. Diretrizes para o uso de tecnologias educacionais. Curitiba: SEED, 2010.

JOLY, M. Introdução à análise de imagens. Campinas: Papirus, 1996.

KENSKI, V. M. O ensino e os recursos didáticos em uma sociedade cheia de tecnologias. In: VEIGA, I. P. A. (Org.). Didática: o ensino e suas relações. Campinas: Papirus, 1996. cap. 7, p.127-147.

MARQUES, A. C.; CAETANO, J. S. Utilização da informática na escola. In: MERCADO, L. P. L. (Org.). Novas tecnologias na Educação: reflexões sobre a prática. Maceió: EDUFAL, 2002. cap. 5 , p. $131-168$.

MAZZOTTI, A. J. A.; GEWANDSZNAJDER, F. O método nas ciências naturais e sociais - pesquisa quantitativa e qualitativa. São Paulo: Pioneira, 1998.

MELO, M. M. M.; ANTUNES, M. C. T. Software livre na educação. In: MERCADO, L. P. L. (Org.). Novas tecnologias na Educação: reflexões sobre a prática. Maceió: Edufal, 2002. 
MERCADO, L. P L. (Org.). Novas tecnologias na educação: reflexões sobre a prática. São Paulo: Edufal, 2002.

NOGAI, M. M. Formação de professores em uma perspectiva reflexiva e o uso do computador no processo de alfabetização com alunas do curso de pedagogia da Universidade Estadual de Maringá - PR. 155 fls. Dissertação (Mestrado em Educação) - Universidade Estadual de Maringá, Maringá, 2005.

PAPERT, S. A máquina das crianças: repensando a escola na era da informática. São Paulo: Bookman, 2007.

PARANÁ. Secretaria do Estado da Educação. Paraná digital: tecnologias de informação e comunicação nas escolas públicas paranaenses. Curitiba: SEED-PR, 2010.

PIAGET, J. O nascimento da inteligência na criança. 4. ed. Rio de Janeiro: Zahar, 1980.

SANTAELLA, L. O que é semiótica. São Paulo: Brasiliense, 2003.

SILVEIRA, S. A. Software livre: a luta pela liberdade do conhecimento. São Paulo: Editora Fundação Perseu Abramo, 2004.

VALENTE, J. A. Formação de professores: diferentes abordagens pedagógicas. In: VALENTE, J. A. (Org.). O computador na sociedade do conhecimento. Campinas: NIED, 1999. cap. 6, p. 131-156.

Submetido em 12/06/2012

Aprovado em 17/02/2014 